\title{
MENERAPKAN TQM (Total Quality Management) DALAM ORGANISASI DAN LEMBAGA PENDIDIKAN
}

Oleh:

\author{
ABDUR ROSID \\ Email: aabanaktobat@gmail.com
}

\begin{abstract}
ABSTRAK
TQM bukanlah inspeksi, melainkan inisiatifyang optimis untuk selalu mencoba mengerjakan segala sesuatu dengan perinsip selalu baik sejak awal. TQM ini juga tidak telepas dari metode-metode dalam pendidikan, oleh karena itu perlu adanya beberapa metode untuk meningkatkan kualitas mutu madrasah. Tujuan dari penerapan TQM itu sendiri untuk mengetahui kualitas mutu dalam madrasah, karena dengan adanya TQM bisa meningkatkan kualitas mutu madrasah.

TQM mendatangkan perubahan yang maksimal terhadap tujuan sebuah organisasi dan lembaga pendidikan dari jangka pendek menuju jangka panjang.

Penerapan TQM terhadap organisasi danpendidikan tidak akan sempurna jika tidak menggunakan metode perbaikan terus menerus dalam meningkatkan kualitas lembaga maupun organisasi.

\section{PENDAHULUAN}

Salah satu tantangan penting yang di hadapi sekolah, perguruan tinggi maupun organisasi adalah cara mengelola sebuah mutu. TQM ialah berpadunya beberapa fungsi dari organisasi (perusahaan/lembaga) ke dalam falsafah berfikirnya orang-orang yang terpacu terhadap mutu, kerja tim, baiknya sumber daya yang membuahkan hasil yang optimal, serta memfokokuskan terhadap kepuasaan pelanggan.TQM di capai dengan ide sentral yang di wujudkan dalam pelaksanaan. Prinsip dasar dari TQM ini adalah bahwa pelanggan dan kepentingannya harus di utamakan. TQM sangat fleksibel dan dapat di adopsi untuk memenuhi kebutuhan khusus maupun institusi, baik secara luas maupun sempit.
\end{abstract}


Di era kontemporer dunia pendidikan di kejutkan dengan adanya modal pengelolaan modal ini mengandaikan adanya upaya pihak pengelola institusi pendidikan untuk meningatkan mutu pendidikan berdasarkan manajemen perusahaan. Strategi yang di kembangkan dalam penggunaan manajemen mutu terpadu dalam dunia pendidikan adalah institusi pendidikan memosisikan dirinya sebagai institusi jasa atau dengan kata lain menjadi indrusti jasa, yakni institusi yang memberikan pelayanan sesuai apa yang diinginkan oleh pelanggan. Dalam operasi TQM dalam dunia pendidikan ada beberpa pokok yang butuh diperhatikan. Pertama, perbaikan secara terus menerus.kedua, menentukan standar mutu.Ketiga, perubahan kultur. Keempat, perubahan organisasi kelima, memperkuat tali solidaritas terhadap pelanggan. Organisasi dan pelanggn harus selalu di pertahankan, supaya institusi pendidikan selalu dapat melakukan perubahan-perubahan yang di perlukan, yang terpenting adalah perubahan sifat dan bentuk tuntutan serta apa yang diinginkan oleh pelanggan. Mutu adalah kepuasan pelanggan sepenuhnya (fullcostumer satisfaction). Untuk mempunyai mutu yang berkualitas harus mengetahui gejala penyebab kesalahan yang terdapat pada proses agar bisa dieliminasi, dari hal itu bisa menghasilakan lulusan-lulusan yang bermutu dan juja memiliki keunggulan sesuai dengan harapan yang diinginkan sebelumnya.

\section{TQM DALAM KONTEKS PENDIDIKAN DAN ORGANISASI}

\section{A. TQM; Beberapa Miskonsepsi}

TQM buknlah inspeksi, melainkan sebuah inisiatif agar melakukan segala sesuatu pekerjaan dengan perinsip selalu baik sejak awal. TQM adalah sebuah filosifi tentang perbaikan secara terus-menerus yang bisa memberikan sebuah alat peraktis kepada setip institusi pendidikan dalam memenuhi kebutuhan dan keinginan pelanggan pada saat ini dan masa yang akan datang. ${ }^{1}$

TQM tidak hanya mengenai seperti apa cara melaksanakan agenda orang lain, melainkan agenda yang sudah disepakati oleh pelanggan dan klien. TQM bukan hanya suatu amanah yang hanya dikerjakan manajer atasan yang selanjutnya

\footnotetext{
${ }^{1}$ Edward Sallis. Total Quality Management in Education,(Yogyakarta:IRCisoD,20015),61-62
} 
mmberikan arahan kepada para bawahannya. Kata "total" (terpadu)dalam TQM mengatakan bahwa setiap orang yang berbaur di dalam organisasi harus teribat dalam proses melakukan peningkatan secara terus menerus.

Program-program TQM tidak hanya menggunakan kata TQM. Beberapa organisasi memsukkan filosofi TQM dengan menggunakan nama yang mereka pilih. Boots the chemist mnyebut program mutu ekstensinya dengan "assured shopping". American exspress menggunakan istilah AEQL (American Exspress Quality Leadership). Organisasi ini lebih menekankan kepemimpinan (leadership) dan bukan manajemen. Total Quality Control, Total Quality Service, Service Quality adalah sebagian dari beberapa nama yang di gunakan beberapa institusi dalam menerngkan TQM. Misal, jika sekolah itu merasa lebih baik dengan mencantumkan nama "pupils first" atau "the school improvement program", maka itu adalah hak mereka. Hal terpenting di sini bukanlah nama, melainkan pengaruh dari program mutu tersebut terhadap kultur sekolah. Pelajar dan orang tua akan tertarik pada perkembangan dan kualitas yang di ciptakan oleh sekolah, bukan hanya terletak pada namanya.

TQM digunakan untuk menjelaskan dua pandangan yang sedikit berbeda, tetapi saling berkaitan. Pertama, melakukanperbaikan secara terus menerus. Kedua, untuk mejelaskan alat-alat dan teknik-teknik, semisal branstorming dan analisis lokasi, yang dipakai untuk peningkatankualitas mutu. TQM yaitu sebuah pola berfikir sekaligus aktivitas praktis.

\section{B. Perbaikan Terus Menerus}

TQM dapat di pahamisebagai filosofi perbaikan tanpa henti sehingga keinginan organisasi dapat di capai dan dengan melibatkan segenap komponen dalam organisasi tersebut.

Semangat tersebut akan menciptakan sebuah proses upaya sadar dalam menganalisis apa yang sedang di kerjakan dan merencanakan perbaikannya. Dalam menciptakan kultur perbaikan terus-menerus, seorang atasan harus mempercayai stafnya dan mendelegasikan hasil keputusan pada tingkatan-tingkatan yang tepat. Hal itubertujuan untuk memberikantanggung jawab untuk mengaplikasikan mutu dalam 
lingkungan mereka. Staf menginginkan kebebasan kerja dalam prosedur kerja yang sudah jelas dan tujuan organisasi yang sudah di prediksi. ${ }^{2}$

\section{Kaizen}

TQM di wujudkan dalam rangkaian proyek-proyek berskala kecil. Kaizen merupakan satu kata yang di miliki oleh jepang yang menjelaskan pendekatan perbaikan terus menerus ini. Terjemahan bebas dari istilah ini adalah perbikan sedikit demi sedikit (step by step improvement). Filosofi TQM memang berskla besar, inspirational dan menyeluruh, tetapi implementai praktisnya justru berskala kecil, sangat praktis, dan berkembang. Intervensi drastis tidak sesuai dengan semangat perubuhan yang ada dalam TQM.

Joseph juran pernah berfikir tentang proyek besar dan kecil. Dia berpendapat bahwa metode yang paling baik dalam melakukan proyek besar adalah dengan memisahkannya ke dalam pekerjaan-pekerjaan kecil yang terkendali. Dia merekomendasikan sebuah tim kerja untuk memilah-milah proyek besar tersebut menjadi kerja-kerja kecil. Sebgaimana kita ketahui, perubahan yang solid dan bertahan lama didasarkan pada kontinutas rangkaian proyek yang kecil dan mungkin.

Dalam dorasi waktu tertentu, cara ini lebih berhasil dari pada langsung melakukan perubhan dalam skala besar. Sepeti ini yang perlu di tekankan untuk melakukan perbikan. Menghabiskan uang tidak dengan sendirinya bisa menghasilkan mutu, meskipun dalam tahap-tahap tertentu dapat membantu.

\section{Perubahan Kultur}

TQM memerlukan perubahn kultur. Ini terkenal sulit untuk diwujudkan dan membutuhkn waktu yang cukup lama. TQM membutuhkan perubhn sikap dan metode. bagaimanapun juga, perubahan kultur tidak hanya bicara tentang mengubah perilku staf,tetapi juga memerlukan perubahan dalam metode pengarahkan sebuah institui. Perubahan metode tersebut ditandai dengan sebuah pemahaman bahwa orang menghasilkan mutu. dua hal yang sngat penting yang dibutuhkan staf untuk menhasilkan mutu. Pertama, staf membutuhkan lingkungan yang nyaman, cocok dan sejahtera dalam bekerja. mereka membutuhkan alat-alat keterampilan, peraturan yang

\footnotetext{
${ }^{2}$ Edward Sallis. Total Quality Management in Education,(Yogyakarta:IRCisoD,20015),64
} 
baik dan motivatif memang tidak serta merta akan menghasilkan mutu, tetapi prosedur yang tidak baikdan salah asuh justru akan membuat mutu menjadi sulit di capai.

Kedua, untuk melakukan pekerjaan dengan baik, staf memerlukan lingkungan yang mendukung dan menghargaikesuksesan dan prestasiyang mereka raih. Mereka memerlukan pemimpin yang dapat menghargai prestasi mereka dan membingbing mereka untuk meraih sukses yang lebih besar. Motivasi untuk mengerjakan pekerjaan yang maksimal yaitu hasil dari sebuah gaya kepemimpinan dan dari atmosfer lingkungan yang dapat menimbulkan kepercayaan diri dalam memberdayakan setiap individu di dalamnya. ${ }^{3}$

\section{E. Organisasi Terbaik}

Dalam TQM, peran manajemen atasan dan menengah adalah mentransfer dukungan dan mutivasi kepada para staf dan pelajar, bukan mengontrol mereka. Hal itu dapat difikirkankan dengan membandingkan bentuk organisasi hierarki tradisional dengan hierarki terbalik TQM. Hierarki yang berupaya untuk mengilustrasikan perubahan paradigma TQM tersebut di adopsi dari ide-ide karl Arbretcht.

Dalam konteks pendidikan, TQM mengubah pola hubungan dengan memberikan sebuah fokus pelanggan yang jelas. Fokus ini tidak berdampak pada struktur otoritas dalam sekolah atau universitas. Ia juga tidak mengurangi peran keoemimpinan manager senior. Kenyataannya, kepemimpinan sangat penting bagi keseuksesan TQM.

\section{F. Memelihara Hubungan dengan Pelanggan}

Misi utama dari sebuah institusi TQM yaituuntuk melengkapi kebutuhan dan inisiatif pelanggannya. Organisasi yang unggul, baik

Negeri maupun suasta adalah organisasi dalam istilah petersdan waterman "menjaga hubungan dengan pelanggannya" dan "memiliki obsesi terhad apmutu". Mutu harus sesuai dengan harapan dan keinginan pelanggan dan klien. Mutu adalah suatu yang di prioritskan terhadap pelanggan dan bukan apa yang terbaik bagi mereka menuruti nstitusi tanpa pelanggan, tidak aka adainstitusi.

${ }^{3}$ Edward Sallis. Total Quality Management in Education,(Yogyakarta:IRCisoD,20015),66-67 
Akan tetapi, focus terhadap pelanggan sajabukan berarti telah memenuhi tuntunan dan persaratan mutu terpadu. Organisasi TQM memerlukan strategi yang berjalan untuk memenuhi keperluan pelanggan.

Pelanggan meiliki fungsi yang unik dalam menentukan mutu apa yang mereka terima dari pendidikan. Ada beberapa masalah menyangkut gagasan konsistensi dalam proses belajar interaktif. Untuk mengatasi masalah tersebut, diperlukan adanya suatu motifasi terhadap para pelajar dan staf yang melayani mereka. Hal penting lainnya adalah memperjelas apa yang ditawarkan konstitusi dan apa yang diharapkan pelajar. ${ }^{4}$

\section{G. MutuPembelajaran}

Pendidikan adalah tentang pembelajaran masyarakat. Untuk memfokuskan diripada aktifitas utama yakni pembelajaran, Semua pelajar berbeda satu sama lainnya, dan mereka belajar dengan model yang cocok dengan kebutuhan dan kecendrungan mereka masing-masing.

Institusi harus memberikan beberapa model pembelajaran dan pengajaran terhadap para pelajar sehingga mereka memiliki kesempatan untuk meraih sukses secar maksimal. ${ }^{5}$

Masih banyak sesuatu yang harus dikerjakan menyinggung bagaimana mengaplikasikan prinsip-prinsip TQM dalam ruang kelas. langkah pertama biasa dimulai dengan kerja sama pelajar dengan dewan guru dalam menentukan misi mereka dari sini, negosiasi bias saja terjadi agar kedua belah pihak biasa mencapai misi bentuk pembelajaran dan pengajaran serta sumber daya yang diperlukan. Masing-masing pelajar bisa membahas keinginan aksi mereka agar mendapatkan mutivasi dana rahan. Proses negosiasi mungkin memerlukan pembentukan sebuah forum yang memberikan umpan balik serta kesempatan kepada para pelajar agar dapat mengatur pembelajaran mereka sendiri. Orang tua atau seponsor kerja dapat menjadi representasi yang baik bagi forum tersebut. Pengawasan yang detail harus

\footnotetext{
${ }^{4}$ Edward Sallis. Total Quality Management in Education,(Yogyakarta:IRCisoD,20015),69-70

${ }_{5}^{5}$ John Miller, Allison Dower, and Sonia Inniss, Improving Quality in Further Education: A Guide for Teachers in Course teams (Ware: Herts, Consultants at Work, 1992).
} 
dilakukan, baik untukpara guru maupun pelajar untuk memastikan bahwa semua telah berjalan sesuai dengan keinginan.

\section{KESIMPULAN}

TQM adalah sebuah filosefi tentang perbaikan secara terus-menerus yang bisa memberikan sebuah cara peraktis kepada setiap institusi pendidikan dalam mencapai kebutuhan, keinginan, dan impian para pelanggannya untuk saat ini dan masa selanjutnya.

Program-program TQM tidak harus menggunakan kata TQM. Beberapa prganisasi memsukkan filosofi TQM dengan menggunakan nama yang mereka pilih. Boots the chemist mnyebut program mutu ekstensinya dengan "assured shopping". American exspress menggunakan istilah AEQL (American Exspress Quality Leadership). Organisasi ini lebih menekankan kepemimpinan (leadership) dan bukan manajemen. Total Quality Control, Total Quality Service, Service Quality adalah sebagian dari beberapa nama yang di gunakan beberapa institusi dalam menerngkan TQM. Misal, jika sekolah tertentu merasa lebih baik memberi nama "pupils first" atau "the school improvement program", maka itu adalah kebebasan mereka. Hal terpenting di sini bukanlh nama, melainkan pengaruh dari program mutu tersebut terhadap kultur sekolah. Pelajar dan orang tua akan tertarik pada perubahan yang di ciptakan oleh sekolah, bukan pada namanya.

Dalam konteks pendidikan, TQM mengubah pola hubungan dengan memberikan sebuah fokus pelanggan yang jelas. Fokus ini tidak berdampak pada struktur otoritas dalam sekolah atau universitas. Ia juga tidak mengurangi peran keoemimpinan manager senior. Kenyataannya, kepemimpinan sangat penting bagi keseuksesan TQM.

Institusi harus memberikan beberapa model pembelajaran dan pengajaran terhadap para pelajar sehingga mereka memiliki kesempatan untuk meraih sukses secar maksimal.

\section{DAFTAR PUSTAKA}


SallisEdward. Total Quality Management in Education,(Yogyakarta:IRCisoD,20015), Miller John, Dower Allison, and Inniss Sonia, Improving Quality in Further Education: A Guide for Teachers in Course teams (Ware: Herts, Consultants at Work, 1992). 
